\title{
Adolescents Perception on Environmental Change and Health Risk in Two Divisions of Bangladesh
}

\author{
Gaylan Peyari Tarannum Dana, Sanjit Roy, Md. Rabuil Haque \\ Department of Population Sciences, University of Dhaka, Dhaka, Bangladesh \\ Email: tarannum_dps@du.ac.bd,sanjit_dps@du.ac.bd,robidps@gmail.com
}

Received 3 November 2015; accepted 11 December 2015; published 14 December 2015

Copyright (C) 2015 by authors and Scientific Research Publishing Inc.

This work is licensed under the Creative Commons Attribution International License (CC BY). http://creativecommons.org/licenses/by/4.0/

(c) (i) Open Access

\section{Abstract}

Bangladesh is facing and will have to face all the direct and indirect impacts of environmental change because of its geographical position. It is one of the developing countries susceptible to environmental disaster where almost each and every year environmental change is affecting the human health in a multi-dimensional way. The linkages between health and environmental change are mediated by the complex interactions of population, society and environmental systems. The objective of this study was to explore adolescents' perception on environmental change and health risk in two divisions of Bangladesh. Our analysis is based on quantitative data collection utilizing structured questionnaires. Simple random sampling was used to have a good representation of population. Total sample size of this study was 437. For the analysis of quantitative data both descriptive and inferential statistics were carried out based on the basis of study objectives. Most of the respondents (98.3\%) stated that environmental change is causing serious health problems in Bangladesh. Majority respondents in Dhaka division perceived that there is an increase in the number of diseases during the summer and respondents in Rajshahi division perceived that number of diseases occur in all three seasons. The study observed that high level of awareness programmes will help to increase the success of different programmes initiated by the government to prevent diseases related to environmental change. Adolescents are aware about the environmental change that is taking place and causing health problems. The most influential factor on such awareness was the excess to receive information those who have information everyday had more knowledge about environmental change and its impact on health. Therefore to increase the knowledge and perception of health problems related to environmental change we need to arrange awareness programme, ensure excess to information and more research in this area.

\section{Keywords}

Adolescent, Environmental Change, Health Risk, Perception, Knowledge, Summer Season, Winter

How to cite this paper: Dana, G.P.T., Roy, S. and Haque, M.R. (2015) Adolescents Perception on Environmental Change and Health Risk in Two Divisions of Bangladesh. Open Journal of Social Sciences, 3, 71-79. 


\section{Season, Rainy Season}

\section{Introduction}

The concept of health includes physical, social and psychological well-being of human population and environmental change has longer impact on health and sustainable human development. The basic and most fundamental conditions of life are linked with environmental changes which are twisted and shaped by the frequency and severity of various climatic events. In recent years a large number of experts identified that knowledge about environmental change is crucial for human health as the occurrence of environmental events contribute to the global burden of diseases and premature deaths in all countries, especially in developing ones [1]. Over the past two decades the issue of environmental change is an evolving concern. The scientist including Intergovernmental Panel on Climate Change (IPCC) have confirmed global warming increasing due to rise in the concentration of greenhouse gases in the atmosphere owing to anthropogenic GHGs emission [2]. In this context environmental change and its impact on health have been concern for all in recent past [3]-[5]. Many countries of the world are frequently experiencing some sort of environmental events, occurring in response to environmental change, which have strong impacts on human health. As a result, there are large numbers of researches going on with the focus to identify that environmental change has possible direct and indirect impacts on health. However, it is yet to be proved that a clear established linkage exists with environmental change and its impacts on health.

Environmental change has posed threats through affecting prerequisite of health and well-being and disturbing the natural ecological systems. Rising levels of global temperatures, anticipated increased rainfall, increasing likelihood of flooding will result in declining crop yields and likelihood of increased epidemics of malaria, dengue, and other vector-borne diseases [6]. WHO estimated that between 2030 and 2050, climate change is expected to cause approximately 250,000 additional deaths per year from malnutrition, malaria, diarrhoea and heat stress [7]. Furthermore WHO noted that climate change is not just a threat to biological systems and the environment but a "significant and emerging threat to public health", especially for those who are living in poverty and vulnerable climate zone [8] [9]. The environmental, social and economic impacts of environmental change are first and most strongly felt by communities who live in ecologically fragile areas [10]. Therefore it is important to know the level of understanding among people how they link environmental change and health problems. Several studies showed that children are worst victim of climate change [11] [12]. Some studies has been carried out both in developed and developing countries to understand the perceptions on the effects of climate change on health among communities [13]-[22]. Toan et al., [23] found in Hanoi that most people had clear perception about climate change and its impact on health. People perceived that health problems usually increase during summer, monsoon and winter season [13] [23] [24]. Other studies reported different categories of health outcomes that are most likely to be affected by environmental change: temperature related health problems; health effects from extreme weather events; air-water related health effects and food and vector borne diseases [25][28]. Akerlof et al., [29] found in USA, Canada and Malta that most people's perceptions on climate change and health risk were consistent with evidence regarding vulnerability of those countries to environmental change. It was found that the people perceived that human health were already being harmed andsaw themselves and their family as being vulnerable to at least moderate harm from climate change.

Bangladesh is one of the developing countries identified as the most susceptible to tropical cyclones, sea level rise and to floods due to its unique geographic location, dominance of floodplains and low elevation from the sea [30]. The country suffers from many kinds of natural disasters that affect an estimated 1.53 million Bangladeshis annually [31]. The Global Climate Risk Index 2014, ranked Bangladesh at $5^{\text {th }}$ position among the world most affected countries from extreme weather events of the last two decades [32]. It is well recognized both in the scientific and negotiating community that Bangladesh would be among most adversely affected countries to climate change [33]. Thereforeenvironmental change stands to pose serious health threats to large sections of Bangladeshi population because we have very high density of population, poor healthcare systems and high levels of widespread poverty. Environmental change have severe consequences on public health in Bangladesh, especially in light of the poor state of the country's public health infrastructure [34]. In Bangladesh, millions of people suffer from diarrhoea, skin diseases, malaria, mental disorders and dengue, etc. [35]. The impact of environmental change on individuals varies according to many factors like age, gender, education, access to in- 
formation, economic status and natural disaster [8] [21] [30] [36].

Currently environmental change is widely being discussed issue nationally and internationally. Many measures has been taken to combat environmental degradation and its impact on health. To the best of our knowledge, most of the earlier researches on environmental change in Bangladesh focused on common issue like climate change and variability; forced migration due to climate change impacts, sea level changes aspects adaptation of climate change, coping strategies to climate change, climate change and adverse effect on health and so on. Limited attention has been given in examining the understanding of adolescent's perception on environmental change and its impact on health. Since adolescents are the future generation, it is important to find out how this group deals environmental change. This paper therefore endeavours to find out adolescent's perception on environmental degradation that have impact on health in two selected areas in Bangladesh. It is expected that findings of this paper will provide valuable insights regarding perception of adolescents on environmental change and its impact to improve the existing policy framework to make prevention measures more effective and to identify areas that require more attention. In addition, this study will generate interest among researchers to carry out further extensive research in this area and contribute to the literature as well.

\section{Methodology}

The study was mainly a quantitative study and the data were collected from Dhaka and Rajshahi divisions with a structured questionnaire. Simple random sampling was used to have a good representation of population. Total sample size of this study was 437. SPSS for windows version-17 was used for data entry and data processing. For the analysis of quantitative data both descriptive and inferential statistics were carried out based on the objective of the study. At the descriptive level, frequency distributions and percentages were calculated. Graphical representations have also been used for understanding the specific consequences properly. Median scores have been incorporated to identify the knowledge level of the respondents regarding environmental changes lead to potential health impact. The respondents who achieved at least median score are treated as they have adequate knowledge about environmental change lead to potential health impact. On the other hand, the respondents who achieved lower than median score are treated as they have no adequate knowledge about it. Finally, at bivariate level, test of association (chi-square) have been used to find out the relationship between different background variables and knowledge level of respondents regarding environmental changes lead to potential health impact which are considered statistically significant at $5 \%$ level.

\section{Results}

Most of the young people of this research fall within the age bracket of 15 to 24 years. Among them $42.7 \%$ belong to age group 15 - 17 and they have been defined as young-young in this study, $25.7 \%$ belong to age group 18 - 22 and they have been defined as young and the rest 31.7\% comprises age group 22+ and they have been defined as late-young in this study. Among the respondents $50.5 \%$ are male and the rest $49.5 \%$ are female. In terms of place of residence $46.9 \%$ respondents have been interviewed from Rajshahi division and the remaining 53.1\% have been interviewed from the Dhaka division. Educational attainment has been classified into two categories namely higher secondary (46.7\%) and Above Higher secondary (53.3\%) (Table 1).

When respondents were asked to give their opinion whether environmental changes are causing serious health problem among the adolescents in Bangladesh. All the respondents perceives that environmental changes are causing serious health problems. In terms of division majority (98.3\%) respondents from Dhaka division reported that they agreed with the opinion, where as in Rajshashi division 58.5\% respondents strongly agreed and $38.5 \%$ agreed with the opnion (see Figure 1).

The knowledge about environmental changes plays acrucial role on the status of our health. To find out the perception about environmental change and health problems, all there spondents of Dhaka division felt that it is important to know about environmental change and its impact on health. Whereas in Rajshahi division 55.1\% respondent felt that it is important and 37.1\% respondent felt it is very important to know about environmental change for health (see Figure 2).

Throughout the year all seasons do not pose same health problems. When ask, the respondents were alert as to which season they face health problems most. According to respondents in terms of season, summer is the time when various kinds of health problems are faced by people compared to winter and rainy season. However by division, it was found that majority (98.7\%) respondents in Dhaka division are facing health problems in summer. 


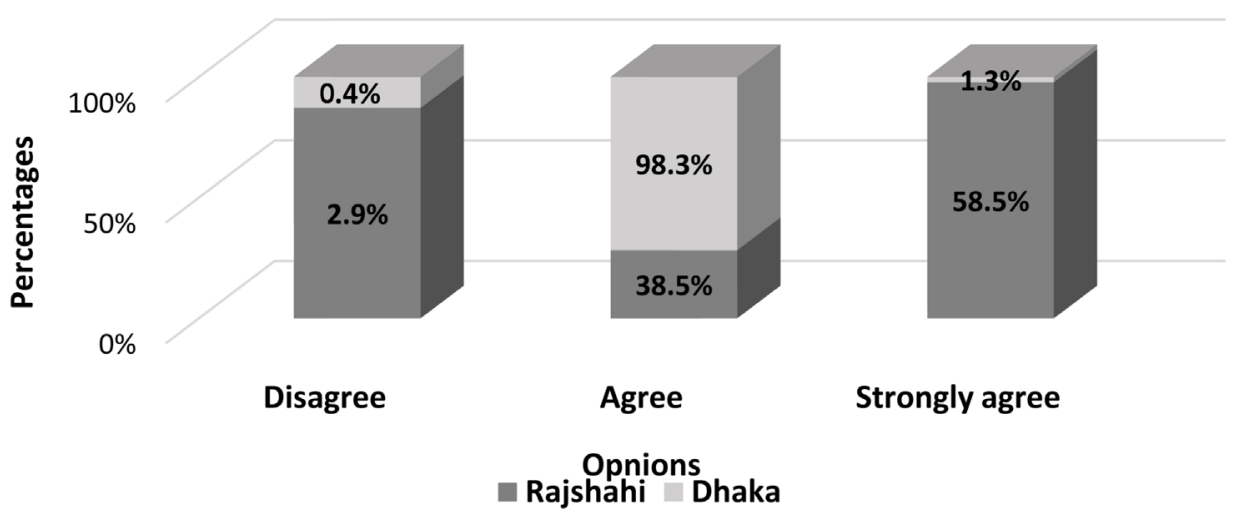

Figure 1. Environmental change causing health problem in Bangladesh.

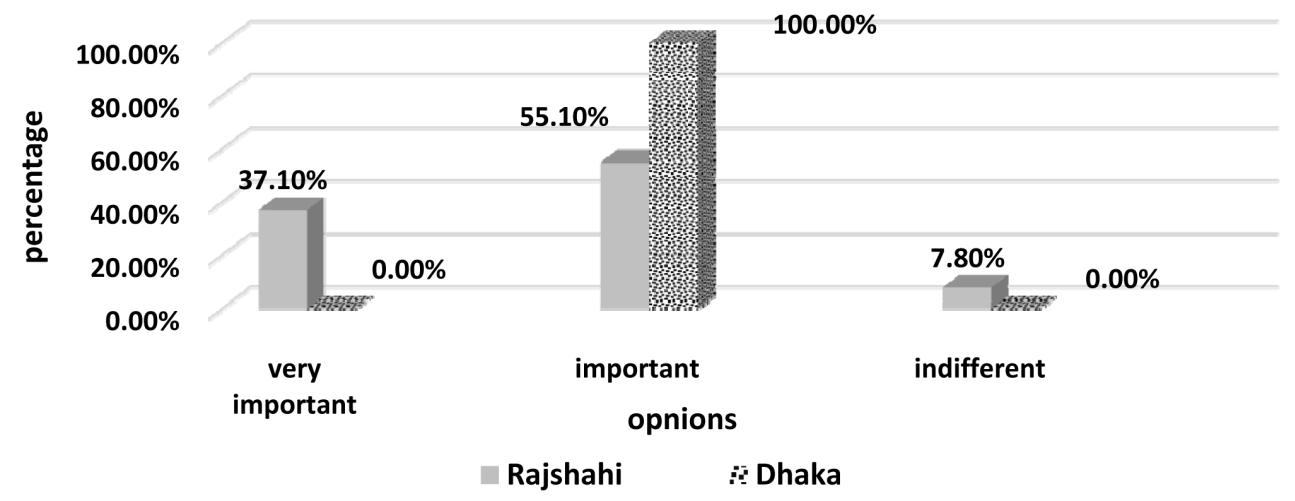

Figure 2. Knowledge on environmental change important for health.

Table 1. Socio-demographic characteristics of the respondents.

\begin{tabular}{|c|c|}
\hline Background Characteristics & Number of respondents (\%) \\
\hline \multicolumn{2}{|c|}{ Age Group } \\
\hline Young-young (15 - 17) & $186(42.7)$ \\
\hline Young (18 - 22) & $112(25.7)$ \\
\hline Late-young (22+) & $138(31.7)$ \\
\hline \multicolumn{2}{|c|}{ Sex } \\
\hline Male & $220(50.5)$ \\
\hline Female & $216(49.5)$ \\
\hline \multicolumn{2}{|c|}{ Place of residence } \\
\hline Rajshahi & 205 (46.9) \\
\hline Dhaka & $232(53.1)$ \\
\hline \multicolumn{2}{|c|}{ Educational attainment } \\
\hline Higher secondary & $204(46.7)$ \\
\hline Above higher secondary & $233(53.3)$ \\
\hline Total & $437(100.0)$ \\
\hline
\end{tabular}

Whilein Rajshahi division more or less they face health problems in all three seasons (see Figure 3).

Moreover, respondents were asked do they think different factors of environmental changes (temperature, changes in the intensity and timing of rainfall, cyclone and drought) are causing serious health problems. In re- 
sponse to these question all respondents of both Dhaka and Rajshahidivision stated that all factors of environmental change are equally triggering serious health problems in the country. However majority of the respondents could not link health hazards with acid rain and sea level rise.

To find out the perception of the respondents about the linkage between knowledge and less disease burden, we have asked them to give their opinion about knowledge on environmental changes reduce the chances to have disease. Almost all the respondents in Dhaka division agreed with the opinion and in Rajshahi Division 49.3\% strongly agreed and $43.9 \%$ agreed with the opinion (see Figure 4 below).

We have asked the respondents thirty questions related to health hazards that are associated to environmental change to measure their knowledge level. Then we have done cross tabulation to examine the association between background variables and the attitude of respondents to causes of environmental change. This study found significant association $(\mathrm{p}=0.000)$ between age and knowledge level of the young people regarding environmental change leading to health problems. More specifically it was found that young-young are significantly more knowledgeable compared to young and late young respectively. We did not find any significant association between sex and adolescent's knowledge about health problems linked with specific environmental changes. However, we have found significant $(\mathrm{p}=0.000)$ differences between the two divisions regarding knowledge level of the adolescents. The level of education has a negative but significant $(p=0.000)$ impact on the knowledge level of the adolescents, that is the increased level of education is not increasing the knowledge level of the adolescents subsequently. This study also found significant $(\mathrm{p}=0.007)$ association between receiving environment related information and the knowledge level of the adolescents regarding health problems linked with specific environmental changes (Table 2).

Nevertheless the test of association (chi-square) shows that the respondents from Dhaka division have significantly higher knowledge compared to Rajshahi division and males have higher knowledge compared to female. However in Dhaka division males are significantly more knowledgeable compared to female and in Rajshahi division inverse scenario has been found (see Table 3). Achieving more knowledge among the male

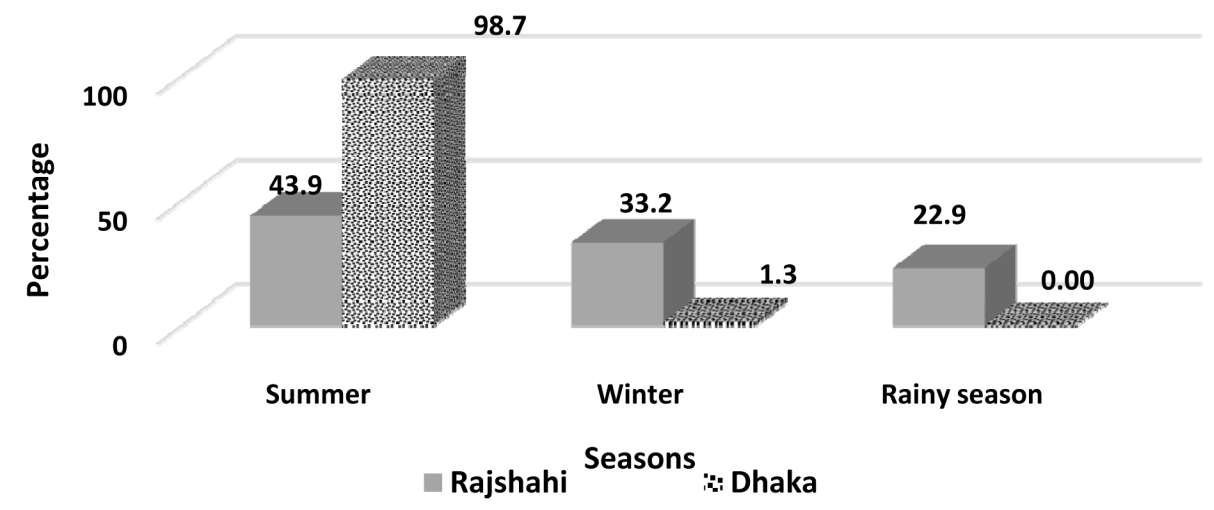

Figure 3. Seasons respondents face more health problem.

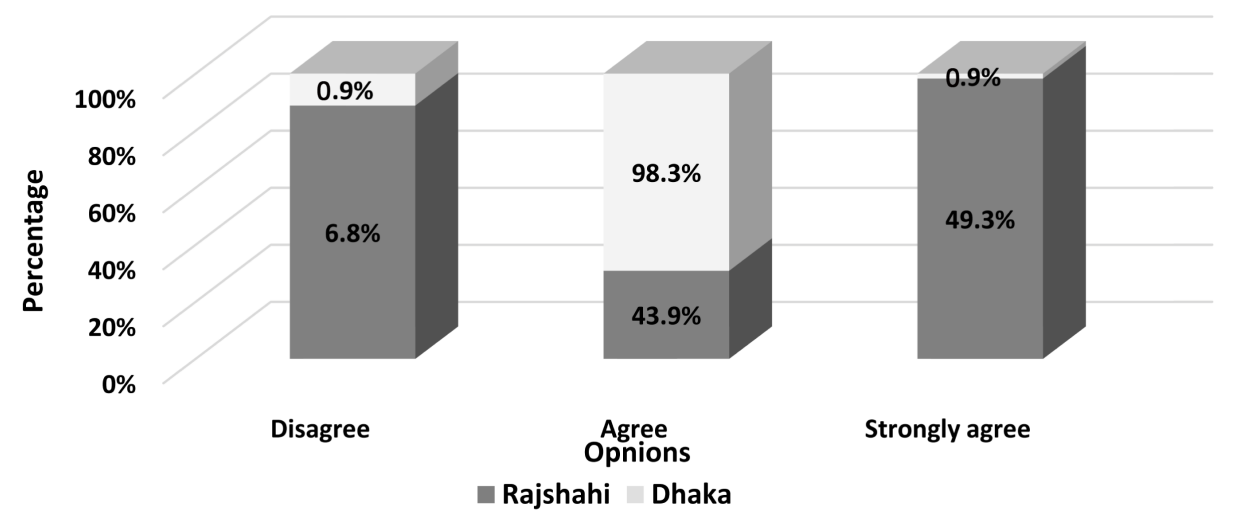

Figure 4. Knowledge on environmental change reduce diseases. 
Table 2. Adolescent's knowledge about health problems linked with specific environmental changes by different backgrounds.

\begin{tabular}{|c|c|c|c|}
\hline Characteristics & No knowledge $N(\%)$ & Have some knowledge $\mathrm{N}(\%)$ & p-value \\
\hline \multicolumn{4}{|l|}{ Age } \\
\hline Young-young (15 - 17) & $42(22.58)$ & $144(77.42)$ & 0.000 \\
\hline Young (18 - 22) & 43 (38.39) & $69(61.61)$ & \\
\hline Late young $(22+)$ & $72(52.17)$ & $66(47.83)$ & \\
\hline \multicolumn{4}{|l|}{ Sex } \\
\hline Male & $77(35.00)$ & $143(65.00)$ & 0.658 \\
\hline Female & $80(37.04)$ & $136(62.96)$ & \\
\hline \multicolumn{4}{|l|}{ Place of residence } \\
\hline Rajshahi & $107(52.20)$ & $98(47.80)$ & 0.000 \\
\hline Dhaka & $51(21.98)$ & $181(78.02)$ & \\
\hline \multicolumn{4}{|l|}{ Education } \\
\hline Higher secondary & $46(22.55)$ & $158(77.45)$ & 0.000 \\
\hline Above higher secondary & $112(48.07)$ & $121(51.93)$ & \\
\hline \multicolumn{4}{|l|}{ Socio-economic status } \\
\hline Deficit & 35 (22.58) & $120(77.42)$ & 0.000 \\
\hline Neither deficit nor surplus & $42(38.18)$ & $68(61.82)$ & \\
\hline Always surplus & $77(45.83)$ & $91(54.17)$ & \\
\hline \multicolumn{4}{|l|}{ Receiving information } \\
\hline Never & $10(62.50)$ & $6(37.50)$ & 0.001 \\
\hline Sometimes & $114(32.11)$ & $241(67.89)$ & \\
\hline Almost everyday & $34(51.52)$ & $32(48.48)$ & \\
\hline
\end{tabular}

Table 3. Adolescent's knowledge about health problems linked with specific environmental changes between male and female respondents by division.

\begin{tabular}{ccccccc}
\hline Division & \multicolumn{3}{c}{ Dhaka division } & \multicolumn{3}{c}{ Rajshahi division } \\
\hline Sex & No knowledge (\%) & $\begin{array}{c}\text { Have some } \\
\text { knowledge (\%) }\end{array}$ & p value & No knowledge (\%) & $\begin{array}{c}\text { Have some } \\
\text { knowledge (\%) }\end{array}$ & p value \\
\hline Male & 12.71 & 87.29 & & 60.78 & 39.22 & \\
Female & 31.58 & 68.42 & 0.001 & 43.14 & 56.86 & 0.012 \\
\hline
\end{tabular}

respondents in Dhaka division is significantly influenced by their educational status as education level is increasing their subsequent knowledge is also increasing. Nonetheless the increased education status have not influenced to increase the knowledge level among the female adolescents regarding environmental change lead to potential health impact in Rajshahi division (table not shown).

\section{Discussion}

The main goal of this study was to examine adolescent's perception on environmental change and related health risks in two divisions of Bangladesh. In this study the average age of the respondents was about 20.07. The study revealed that in both divisions adolescents have clear perception about environmental changes causing serious health problem in Bangladesh. The afore mentioned opinion conform with the ones listed by Haque et al., [13] Aoyagi [37], Manuti, [38] and Asekun-Olarinmoye, [3]. As regards which season they face more health 
problems most of the respondents of Dhaka stated that major health problems are faced in summer compared to winter and rainy seasons. Whereas in the Rajshahi division they face health problems throughout the year in all seasons.In similar other studies also upholds our findings, perception about health problems in summer, winter and rainy season have been pointed out in order of importance ([3] [6] [11] [13] [23] [39]).

In this study the number of male and female were almost equal but their perception in relation to environmental change causing health problems were different. In Dhaka division it was found that male respondents have more knowledge compared to female respondents. Similar observation has been made in other studies where gender perspective regarding environmental change was significant because information relating to this is limited especially in third world countries [16] [23] [40]-[43]. Similar to this research McCright [44] suggested gender differences may stem from differing socialization experiences between men and women, which can lead to differing levels of environmental concern or trust in science. As regards the effects of environmental change on health, most respondents stated that environmental change lead to ill health. Further in both the divisions we found that majority respondents stated that clear perception on environmental changes reduce the chance to have diseases. This supports another study with similar findings [3] [11] [23] [39] [45]-[47].

\section{Conclusion and Recommendation}

The study had some limitations. Firstly the study was conducted at the divisional level only so it may not represent the perceptions of elsewhere. Secondly the issues under this study are complicated and difficult to measure as recall bias and subject to personal judgment. Our study revealed that high proportion of the respondent in both the divisions perceived that environmental change is causing health problems in Bangladesh. The respondents could mention in which season health problems are occurring more. The most influential factor of such awareness was the excess to receive information those who have information everyday had more knowledge about environmental change and its impact on health. Furthermore the study reveals that respondents had strong perception that more knowledge on environmental change can help to avoid health problems. However with the increase level of education respondents had lesser knowledge about environmental change and its impact on health. Therefore in order to increase the knowledge, improve the attitudes and practices of communities with regard to environmental change issues and its impact on health following suggestions need to be considered:

$>$ Arrange more practical awareness programme to have clear perception on different environmental issues that have potential threat on health; also, indigenous knowledge system should complement global modern knowledge systems to enhance climate change mitigation.

$>$ Need to establish locally based institutions for providing regular information on environmental change and its impact on health.

$>$ Increase awareness campaign with greater focus on adolescents at higher educational level.

$>$ More education and rising awareness programme required for adolescents to appreciate that environmental change is a public health issue.

$>$ Need to improve the national prevention programme on environmental change by including the health aspect.

$>$ More research is needed to identify critical issues of climate change and the associations between health and nonfatal illnesses.

\section{Acknowledgements}

We would like to thank UNFPA for granting us the fund to do the research. We also like to thank all the data collectors and respondents who have participated in this research.

\section{Competing Interest}

The authors declare that they have no competing interests.

\section{References}

[1] Grasso, M., et al. (2012) The Health Effects of Climate Change: A Survey of Recent Quantitative Research. International Journal of Environmental Research and Public Health, 9, 1523-1547. http://dx.doi.org/10.3390/ijerph9051523

[2] Bernstein, L., et al. (2007) Climate Change 2007: Synthesis Report: Intergovernmental Panel on Climate Change. No- 
vember.

[3] Esther, A.O., et al. (2014) Public Perception of Climate Change and Its Impact on Health and Environment in Rural Southwestern Nigeria.

[4] Costello, A., et al. (2009) Managing the Health Effects of Climate Change: Lancet and University College London Institute for Global Health Commission. The Lancet, 373, 1693-1733. http://dx.doi.org/10.1016/S0140-6736(09)60935-1

[5] Keim, M.E. (2008) Building Human Resilience: The Role of Public Health Preparedness and Response as an Adaptation to Climate Change. American Journal of Preventive Medicine, 35, 508-516. http://dx.doi.org/10.1016/j.amepre.2008.08.022

[6] Mishra, S.R., et al. (2015) Climate Change and Adverse Health Events: Community Perceptions from the Tanahu District of Nepal. Environmental Research Letters, 10, 034007. http://dx.doi.org/10.1088/1748-9326/10/3/034007

[7] World Health Organization (2014) Quantitative Risk Assessment of the Effects of Climate Change on Selected Causes of Death, 2030s and 2050s. World Health Organization.

[8] Be, T.T., Sinh, B.T. and Miller, F. (2007) Challenges to Sustainable Development in the Mekong Delta-Regional and National Policy Issues and Research Needs. Bangkok, Thailand: The Sustainable Mekong Research Network (SUMERNET), 143 Á188.

[9] Parry, M.L. (2007) Climate Change 2007: Impacts, Adaptation and Vulnerability: Contribution of Working Group II to the Fourth Assessment Report of the Intergovernmental Panel on Climate Change. Vol. 4. Cambridge University Press.

[10] Lama, S. and Devkota, B. (2009) Vulnerability of Mountain Communities to Climate Change and Adaptation Strategies. Journal of Agriculture and Environment, 10, 76-83. http://dx.doi.org/10.3126/aej.v10i0.2133

[11] Sheffield, P.E. and Landrigan, P.J. (2010) Global Climate Change and Children's Health: Threats and Strategies for Prevention. Environmental Health Perspectives, 119, 291-298. http://dx.doi.org/10.1289/ehp.1002233

[12] Landrigan, P.J., Kimmel, C.A., Correa, A. and Eskenazi, B. (2004) Children's Health and the Environment: Public Health Issues and Challenges for Risk Assessment. Environmental Health Perspectives, 112, 257-265.

[13] Haque, M.A., Yamamoto, S.S., Malik, A.A. and Sauerborn, R. (2012) Households' Perception of Climate Change and Human Health Risks: A Community Perspective. Environmental Health, 11, 1. http://dx.doi.org/10.1186/1476-069X-11-1

[14] DeBono, R., Vincenti, K. and Calleja, N. (2012) Risk Communication: Climate Change as a Human-Health Threat, a Survey of Public Perceptions in Malta. European Journal of Public Health, 22, 144-149. http://dx.doi.org/10.1093/eurpub/ckq181

[15] Chaudhary, P. and Bawa, K.S. (2011) Local Perceptions of Climate Change Validated by Scientific Evidence in the Himalayas. Biology Letters, rsbl20110269. http://dx.doi.org/10.1098/rsbl.2011.0269

[16] Preet, R., Nilsson, M., Schumann, B. and Evengård, B. (2010) The Gender Perspective in Climate Change and Global Health. Global Health Action, 3, 5720. http://dx.doi.org/10.3402/gha.v3i0.5720

[17] Alam, K., Naureen, F. and Wahida, B. (2008) Gender, Climate Change and Human Security in Bangladesh. Action Aid, Dhaka.

[18] Emch, M., Feldacker, C., Yunus, M., Streatfield, P.K., DinhThiem, V., Canh do, G. and Ali, M. (2008) Local Environmental Predictors of Cholera in Bangladesh and Vietnam. The American Journal of Tropical Medicine and Hygiene, 78, 823-832.

[19] McMichael, A.J. and Butler, C.D. (2006) Emerging Health Issues: The Widening Challenge for Population Health Promotion. Health Promotion International, 21, 15-24. http://dx.doi.org/10.1093/heapro/dal047

[20] Leiserowitz, A.A. (2005) American Risk Perceptions: Is Climate Change Dangerous? Risk Analysis, 25, $1433-1442$. http://dx.doi.org/10.1111/j.1540-6261.2005.00690.x

[21] Dolan, A.H. and Walker, I. (2006) Understanding Vulnerability of Coastal Communities to Climate Change Related Risks. Journal of Coastal Research, Special Issue No. 39, 1316-1323.

[22] Gonzalez, L.E. and Da Silveira, P. (1997) The People’s Attitudes towards Global Environmental Phenomena: A Case Study. Climate Research, 9, 95-100. http://dx.doi.org/10.3354/cr009095

[23] Toan, D.T.T., Kien, V.D., Bao Giang, K., Van Minh, H. and Wright, P. (2013) Perceptions of Climate Change and Its Impact on Human Health: An Integrated Quantitative and Qualitative Approach. Global Health Action, 7, 23025.

[24] Nesha, M.K., Rahman, A.A., Hasan, K. and Ahmed, Z. (2014) People’s Perception in Relation to Climate Change and Its Adverse Effects in Rural Bangladesh. Journal of Environment and Human, 1, 23-33. http://dx.doi.org/10.15764/EH.2014.03003

[25] Egondi, T., Kyobutungi, C., Ng, N., Muindi, K., Oti, S., van de Vijver, S., Ettarh, R. and Rocklöv, J. (2013) Community Perceptions of Air Pollution and Related Health Risks in Nairobi Slums. International Journal of Environmental Research and Public Health, 10, 4851-4868. http://dx.doi.org/10.3390/ijerph10104851 
[26] Frumkin, H., Hess, J., Luber, G., Malilay, J. and McGeehin, M. (2008) Climate Change: The Public Health Response. American Journal of Public Health, 98, 435-445. http://dx.doi.org/10.2105/AJPH.2007.119362

[27] Haines, A., Kovats, R.S., Campbell-Lendrum, D. and Corvalan, C. (2006) Climate Change and Human Health: Impacts, Vulnerability and Public Health. Public Health, 120, 585-596. http://dx.doi.org/10.1016/j.puhe.2006.01.002

[28] Patz, J.A., McGeehin, M.A., Bernard, S.M., Ebi, K.L., Epstein, P.R., Grambsch, A., et al. (2000) The Potential Health Impacts of Climate Variability and Change for the United States: Executive Summary of the Report of the Health Sector of the US National Assessment. Environmental Health Perspectives, 108, 367-376.

[29] Akerlof, K., DeBono, R., Berry, P., Leiserowitz, A., Roser-Renouf, C., Clarke, K.-L., et al. (2010) Public Perceptions of Climate Change as a Human Health Risk: Surveys of the United States, Canada and Malta. International Journal of Environmental Research and Public Health, 7, 2559-2606. http://dx.doi.org/10.3390/ijerph7062559

[30] MoEF (2009) Bangladesh Climate Change Strategy and Action Plan 2009.

[31] Guha-Sapir, D., Philippe, H. and Below, R. (2013) Annual Disaster Statistical Review 2013. The Numbers and Trends. Centre for Research on the Epidemiology of Disasters (CRED), Institute of Health and Society (IRSS), Université catholique de Louvain, Brussels.

[32] Kreft, S., Eckstein, D., Junghans, L., Kerestan, C. and Hagen, U. (2014) Global Climate Risk Index 2015.

[33] Mahmood, S.S., Najneen, F., Hoque, K.S., Rahman, S. and Shamim, M. (2010) Climate Change: A Study on Impact and People's Perception (a Case Study on Mongla Upazila, Bagerhat District, Bangladesh). Bangladesh Research Publications Journal, 4, 153-164.

[34] Shahid, S. (2010) Probable Impacts of Climate Change on Public Health in Bangladesh. Asia-Pacific Journal of Public Health, 22, 310-319. http://dx.doi.org/10.1177/1010539509335499

[35] Rahman, A. (2008) Climate Change and Its Impact on Health in Bangladesh. Regional Health Forum, 12, 16-26.

[36] Bank, T. (2010) Public Attitudes toward Climate Change: Findings from a Multicountry Poll. The World Bank, Washington DC, 1 Á83.

[37] Aoyagi-Usui, M. (2008) An Analysis of the Effective Factors for Promoting Proenvironmental Actions from the Information Gain and Social Capital Point of View. Review of Environmental Economics and Policy Studies, 1, 37-50.

[38] Manuti, A. (2013) Climate Change Awareness: An Explorative Study on the Discursive Construction of Ethical Consumption in a Communication Campaign. American Journal of Applied Psychology, 1, 65-71.

[39] Syal, S.S., Wilson, R.S., Crawford, J.M. and Lutz, J. (2011) Climate Change and Human Health-What Influences the Adoption of Adaptation Programming in the United States Public Health System? Mitigation and Adaptation Strategies for Global Change, 16, 911-924. http://dx.doi.org/10.1007/s11027-011-9302-1

[40] Stevenson, K.T., Peterson, M.N., Bondell, H.D., Moore, S.E. and Carrier, S.J. (2014) Overcoming Skepticism with Education: Interacting Influences of Worldview and Climate Change Knowledge on Perceived Climate Change Risk among Adolescents. Climatic Change, 126, 293-304. http://dx.doi.org/10.1007/s10584-014-1228-7

[41] Mamun, S., Nessa, A., Aktar, M., Hossain, M.R. and Saifullah, A.S.M. (2013) Perception of Environmental Education and Awareness among Mass People: A Case Study of Tangail District. Journal of Environmental Science and Natural Resources, 5, 263-266. http://dx.doi.org/10.3329/jesnr.v5i2.14828

[42] Stott, R. (2010) Population and Climate Change: Moving toward Gender Equality Is the Key. Journal of Public Health, 32, 159-160. http://dx.doi.org/10.1093/pubmed/fdq040

[43] Carew-Reid, J. (2008) Rapid Assessment of the Extent and Impact of Sea Level Rise in Viet Nam. International Centre for Environment Management (ICEM), Brisbane, 82.

[44] McCright, A.M. (2010) The Effects of Gender on Climate Change Knowledge and Concern in the American Public. Population and Environment, 32, 66-87. http://dx.doi.org/10.1007/s11111-010-0113-1

[45] Haque, M.A., Budi, A., Malik, A.A., Yamamoto, S.S., Louis, V.R. and Sauerborn, R. (2013) Health Coping Strategies of the People Vulnerable to Climate Change in a Resource-Poor Rural Setting in Bangladesh. BMC Public Health, 13, 565. http://dx.doi.org/10.1186/1471-2458-13-565

[46] Kien, T.M., Hanh, T.T.T., Cuong, H.D. and Shaw, R. (2010) Identifying Linkages between Rates and Distributions of Malaria, Water-Born Diseases and Influenza with Climate Variability and Climate Change in Vietnam. In: Shaw, R., Pulhin, J.M. and Pereira, J.J., Eds., Climate Change Adaptation and Disaster Risk Reduction: An Asian Perspective, Chap. 20, Emerald Group Publishing Limited, Bingley, 417-449. http://dx.doi.org/10.1108/S2040-7262(2010)0000005026

[47] Semenza, J.C., Hall, D.E., Wilson, D.J., Bontempo, B.D., Sailor, D.J. and George, L.A. (2008) Public Perception of Climate Change: Voluntary Mitigation and Barriers to Behavior Change. American Journal of Preventive Medicine, 35, 479-487. http://dx.doi.org/10.1016/j.amepre.2008.08.020 